\title{
A DEA application for analyzing investment activities in higher educational organizations
}

\author{
Zahra Azizi $^{\mathrm{a}^{*}}$ and Mehdi Paktinat ${ }^{\mathrm{b}}$
}

${ }^{a}$ Department of Accounting, Science and Research Branch, Islamic Azad University, Saveh, Iran ${ }^{b}$ Department of Industrial management, Semnan Branch, Islamic Azad University, Semnan, Iran

CHRON I C LE ABSTRACT

\section{Article history:}

Received October 12, 2012

Received in revised format

29 November 2012

Accepted 28 December 2012

Available online

January 42013

Keywords:

DEA

Efficiency

University

\section{Introduction}

Private schools play important role on developing economy especially in rural areas of Iran and when they operate efficiently it can also be considered as a rich source of income. During the past three decades, data envelopment analysis (DEA) (Charnes et al., 1978, 1994; Andersen et al., 1993) has become a popular technique for measuring the relative performance of non-financial units. Fallah et al. (2011) used DEA analysis on banking sector by considering various financial and non-financial inputs and outputs and measured the relative efficiencies of various branches of banks and analyzed them under different scenarios. Avkiran (2010) studied the relationship between the supper-efficiency estimations and some major important financial ratios for some Chinese banking sector. The survey provided found the inefficient units where there was a low correlation between the supper-efficiency and desirable financial ratios. Staub et al. (2010) studied different factors affecting the relative efficiency of Brazilian banks including cost and technical efficiencies over the period 2000-2007.

\footnotetext{
*Corresponding author.

E-mail addresses: danaei11@yahoo.com (Z. Azizi)

C 2013 Growing Science Ltd. All rights reserved. doi: $10.5267 /$ j.msl.2013.01.004
} 
Lin et al. (2009) used different DEA methods for 117 branches of a certain bank in Taiwan and reported an overall technical efficiency of 54.8\% among them. Yang et al. (2010) studied bank performance and management planning based on hybrid minimax reference point - DEA approach. Zaheri et al. (2012) investigated customer loyalty and prioritizing based one private bank in Kurdistan province.

In this paper, we present an empirical study to measure the relative efficiency of 11 private universities located in region ten of Islamic Azad university. The organization of the paper first presents details of the propsoed method in section 2. The results are discussed in section 3 and concluding remarks are given in the last to summarize the contribution of the paper.

\section{The proposed study}

The proposed study of this paper uses DEA as a primary tool for measuring the relative performance of all Islamic Azad university, which are active in region ten and the primary objective is to look for investment activities accomplished during the fiscal year of 2011. Fig. 1 demonstrates the structure of the proposed study of this paper.

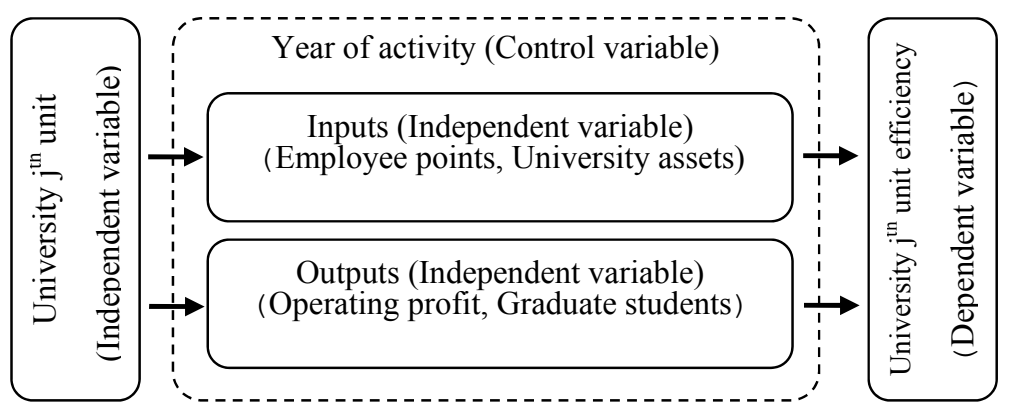

Fig. 1. The framework of the proposed study

The proposed study is considered as an applied research and the purpose of the research is to measure the relative performance of the biggest university units in region 10 in terms of investment activities. Fig. 2 demonstrates details of our proposed study.

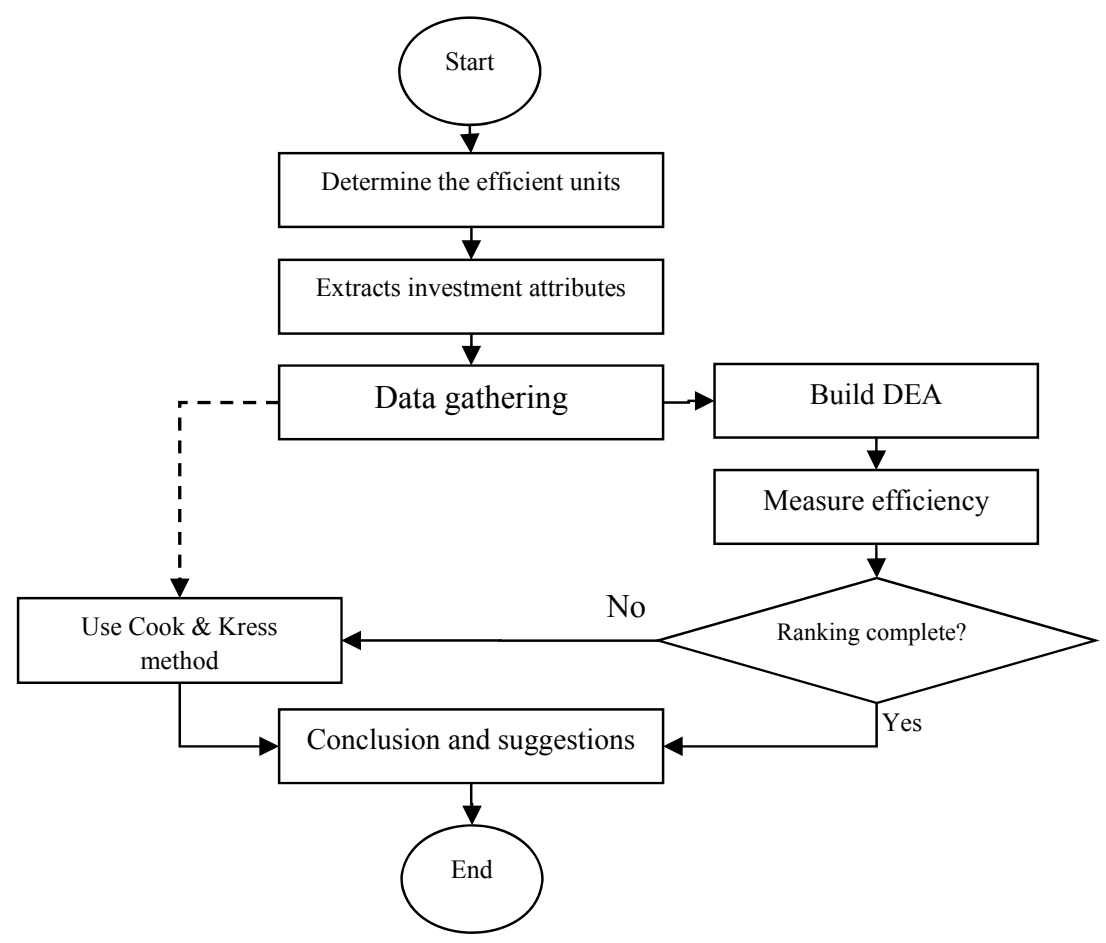

Fig. 2. The procedure of the proposed study 
In our study, we investigate whether we could improve the relative efficiency of a particular unit through merging the unit with another unit. We also perform an investigation to detect the best model for measuring the relative efficiency.

Charnes, et al. $(1978,1994)$ are believed to be the first who introduced the idea of constant return to scale DEA (CCR) as a mathematical technique for measuring the relative efficiency of decision making units (DMU).

It is an easy task to show that DMU works whenever a production function is available. However, in different cases obtaining an analytical form for this function is not practical. Therefore, we form a set of production feasibility, which includes some principles such as fixed-scale efficiency, convexity and feasibility as follows,

$$
T_{C}=\left\{(X, Y) \mid X \geq \sum_{j=1}^{n} \lambda_{j} X_{j}, Y \leq \sum_{j=1}^{n} \lambda_{j} Y_{j}, \lambda_{j} \geq 0, j=1, \cdots n\right\},
$$

where $X$ and $Y$ are input and output vectors, respectively. The CCR production feasibility set border defines the relative efficiency in which any off-border DMU is considered as inefficient point. The CCR model is determined in two forms of either input or output oriented.

The input CCR aims to decrease the maximum input level with a ratio of $\theta$ so that, at least, the same output is produced, i.e.:

$\min \theta$

subject to

$$
\begin{aligned}
& \theta X_{p}-\sum_{j=1}^{n} \lambda_{j} X_{i j} \geq 0, \\
& \sum_{j=1}^{n} \lambda_{j} Y_{r j} \geq Y_{r p}, \\
& \sum_{j=1}^{n} \lambda_{j}=1, \\
& \lambda_{j} \geq 0, \quad j=1, \cdots, n .
\end{aligned}
$$

Model (2) is called DEA form of input CCR where $\theta$ is the relative efficiency of the DMU and we can verify that the optimal value of $\theta, \theta^{*}$, is a number between zero and one. We may write the dual of model (2) as follows,

$$
\begin{aligned}
& \min \sum_{r=1}^{s} u_{r} y_{r 0}+u_{0} \\
& \text { subject to } \\
& \sum_{i=1}^{m} v_{i} X_{i 0}=1 \\
& \sum_{i=1}^{m} v_{i} X_{i 0}-{ }_{i p} \sum_{i=1}^{m} v_{i} X_{i j}+u_{0} \leq 0, \quad j=1, \cdots, n . \\
& u_{r} \geq 0, \quad r=1, \cdots, s . \\
& v_{i} \geq 0, \quad i=1, \cdots, m
\end{aligned}
$$

In case we consider the dual fuzzy two-phase BCC form, the first phase is as follows, 
$\max : \phi$

subject to

$$
\begin{array}{ll}
\sum_{j=1}^{n} \mu_{j} x_{i j} \leq x_{i 0} \quad, \quad i=1, \ldots, m \\
\sum_{j=1}^{n} \mu_{j} y_{r j} \geq \phi y_{r 0} \quad, \quad r=1, \ldots, s \\
\sum_{j=1}^{n} \mu_{j}=1 \quad, \quad j=1, \ldots, n \\
\mu_{j} \geq 0 \quad, j=1, \ldots, n
\end{array}
$$

$\phi$ free.

In addition, the second phase of fuzzy BCC is as follows,

$\max : \quad w=\sum_{i=1}^{m} S_{i}^{-}+\sum_{r=1}^{s} S_{r}^{+}$

subject to

$$
\begin{aligned}
& \sum_{j=1}^{n} \mu_{j} x_{i j}+S_{i}^{-}=x_{i 0}, \quad i=1, \ldots, m \\
& \sum_{j=1}^{n} \mu_{j} y_{r j}-S_{r}^{+}=\phi^{*} y_{r 0}, \quad r=1, \ldots, s \\
& \sum_{j=1}^{n} \mu_{j}=1, \quad j=1, \ldots, n \\
& \mu_{j} \geq 0, \quad j=1, \ldots, n \quad S_{i}^{-} \geq 0, \quad i=1, \ldots, m \quad S_{r}^{+} \geq 0, r=1, \ldots, s .
\end{aligned}
$$

One of the issues associated with DEA method arises when some of the dual variables appear to be zero in optimality. In such a case, there are more than one inefficient unit and two units having the same output and different inputs could both be considered inefficient with the ratios. This is not a correct observation since one unit is more efficient that the other one. In such a case we may use an approach developed by Cook and Kress (1990). The model presents the best model for collection ballot voting results and for each candidate, it provides a fair assessment for the first, the second and other candidates. Let $\mathrm{y}_{\mathrm{rj}}$ be the total number of votes for candidate $\mathrm{j}^{\text {th }}$ and $\varepsilon$ be a small number as a lower bound for decision making unit. For the sake of simplicity we consider $d(r, \varepsilon)=\varepsilon$. Therefore we have,

$\max \sum_{r=1}^{s} u_{r} y_{r o}$

subject to

$$
\begin{aligned}
& \sum_{r=1}^{s} u_{r} y_{r j} \leq 1, \quad j=1, \ldots, n \\
& u_{r}-u_{r+1}-d(r, \varepsilon) \geq 0 \\
& u_{r}-d(r, \varepsilon) \geq 0
\end{aligned}
$$




\section{The results}

In this section, we present the results of the implementation of our proposed study. The proposed study of this paper assigns some points for human resources including university professor and regular employees and considers it along with assets as inputs of DEA model. Table 1 demonstrates inputs/outputs of the proposed model.

Table 1

Inputs/outputs of the proposed model

\begin{tabular}{lcccc}
\hline \multirow{2}{*}{ Unit } & \multicolumn{2}{c}{ Inputs } & \multicolumn{2}{c}{ Outputs } \\
\cline { 2 - 5 } Assets & Human resource points & Graduated students & Operating profit \\
\hline Bzad shahr (1) & $71,689.03$ & 8100 & 1231 & 25386 \\
Damdar Gaz (2) & $60,203.25$ & 2429 & 300 & -4895 \\
Semghan (3) & $119,107.46$ & 10658 & 984 & -14016 \\
Shahrood (5) & $94,187.98$ & 15228 & 1860 & -31093 \\
Aliabad (6) & $123,795.47$ & 24676 & 1763 & -11436 \\
Gorgan (7) & $162,375.92$ & 13333 & 1143 & -13490 \\
Garmsar (8) & $98,131.66$ & 11886 & 1407 & -34937 \\
Mahdishahr (9) & $145,483.24$ & 18951 & 1460 & -14359 \\
Gonbad Kaboos (10) & $8,983.98$ & 2953 & 100 & -2795 \\
Minoodasht(11) & $12,414.07$ & 3262 & 185 & -7478 \\
\hline & & 2220 & 213 & -4252 \\
\hline
\end{tabular}

Applying DEA method using BCC technique helps determine relative efficiencies of the proposed model summarized in Table 2 as follows.

Table 2

The results of relative efficiency

\begin{tabular}{llllllllllll}
\hline Unit & 1 & 2 & 3 & 4 & 5 & 6 & 7 & 8 & 9 & 10 & 11 \\
\hline Efficiency & 1 & 1 & 0.68 & 1 & 1 & 0.68 & 0.90 & 0.83 & 1 & 0.50 & 1 \\
Eff./Ineff. & $\sqrt{ }$ & $\sqrt{ }$ & - & $\sqrt{ }$ & $\sqrt{ }$ & - & - & - & $\sqrt{ }$ & - & $\sqrt{ }$ \\
Rank & 1 & 1 & 9 & 1 & 1 & 9 & 7 & 8 & 1 & 11 & 1 \\
\hline
\end{tabular}

We have calculated how we can improve the relative efficiency of inefficient units to become efficient and the results are summarized in Table 3.

Table 3

The results of necessary improvement required to convert inefficient units to efficient ones

\begin{tabular}{lcccc}
\hline \multirow{2}{*}{ Unit } & \multicolumn{2}{c}{ Present output } & \multicolumn{2}{c}{ Ideal output } \\
\cline { 2 - 5 } & $\begin{array}{c}\text { Graduated } \\
\text { students }\end{array}$ & Operating profit & Graduated students(Gap) & $\begin{array}{c}\text { Operating } \\
\text { profit(Gap) }\end{array}$ \\
\hline Azad shahr (1) & 1231 & 25386 & - & - \\
Bandar Gaz (2) & 300 & -4895 & - & $5117.58(68 \%)$ \\
Damghan (3) & 984 & -14016 & $1457(41 \%)$ & - \\
Semnan (4) & 1860 & -31093 & - & $-5186.46(72 \%)$ \\
Shahrood (5) & 1763 & -11436 & $1586(40 \%)$ & $-4612.53(90)$ \\
Aliabad (6) & 1143 & -13490 & $1565(104 \%)$ & $-10976.8(86)$ \\
Gorgan (7) & 1407 & -34937 & $1699(43 \%)$ & - \\
Garmsar (8) & 1460 & -14359 & - & $676.28(52)$ \\
Mahdishahr (9) & 100 & -2795 & $359(22)$ & - \\
\hline Gonbad Kaboos (10) & 185 & -7478 & - & - \\
Minoodasht(11) & 213 & -4252 & - & - \\
\hline
\end{tabular}


Table 3 shows the amount of additional output each inefficient unit needs to add to become efficient one. The results also demonstrate the relative gap between actual and desirable outputs. In addition, as we can observe from the results of Table 3, six out of eleven units have become efficient. Therefore, we need to use Cook and Kress (1990) method to rank efficient units and we first report cross DEA for measuring relative efficiency of various units based on BCC method and Table 4 summarizes the results. In addition, Table 5 shows details of ranking based on the results of Table 4 .

\section{Table 4}

The summary of relative efficiency using Cross DEA using BCC technique

\begin{tabular}{rccrrrrrrrrc}
\hline Unit & $(1)$ & $(2)$ & $(3)$ & $(4)$ & $(5)$ & $(6)$ & $(7)$ & $(8)$ & $(9)$ & $(10)$ & $(11)$ \\
\hline$(1)$ & 100 & - & 74.788 & 55.351 & 33.952 & 60.406 & 68.921 & 43.373 & - & - & - \\
$(2)$ & 30.335 & 100 & 21.852 & 18.279 & 11.077 & 18.087 & 21.441 & 13.593 & 63.333 & 58.686 & 86.885 \\
$(3)$ & 81.529 & - & 67.56 & 45.526 & 27.889 & 49.185 & 56.334 & 35.479 & - & - & - \\
$(4)$ & - & - & - & 100 & 61.256 & - & - & 77.002 & - & - & - \\
$(5)$ & - & - & - & - & 100 & - & - & - & - & - & - \\
$(6)$ & 93.419 & - & 69.786 & 51.85 & 31.792 & 67.56 & 64.437 & 40.561 & - & - & - \\
$(7)$ & - & - & 84.526 & 68.235 & 41.614 & 69.197 & 90.09 & 51.557 & - & - & - \\
$(8)$ & - & - & 91.475 & 73.142 & 44.648 & 74.742 & 87.72 & 82.64 & - & - & - \\
$(9)$ & - & - & - & - & - & - & - & - & 100 & - & - \\
$(10)$ & 36.462 & 64.913 & 24.295 & 25.424 & 15.157 & 21.081 & 26.995 & 17.349 & 45.726 & 49.5 & 67.854 \\
$(11)$ & - & 83.334 & - & - & - & - & - & - & - & - & 100 \\
\hline
\end{tabular}

Table 4

The summary of ranks of various units using Cross DEA using BCC technique

\begin{tabular}{rccccccccccc}
\hline Unit & $(1)$ & $(2)$ & $(3)$ & $(4)$ & $(5)$ & $(6)$ & $(7)$ & $(8)$ & $(9)$ & $(10)$ & $(11)$ \\
\hline$(1)$ & 1 & - & 3 & 4 & 5 & 4 & 3 & 4 & - & - & - \\
$(2)$ & 5 & 1 & 7 & 8 & 9 & 7 & 7 & 8 & 2 & 1 & 2 \\
$(3)$ & 3 & - & 5 & 6 & 7 & 5 & 5 & 6 & - & - & - \\
$(4)$ & - & - & - & 1 & 2 & - & - & 2 & - & - & - \\
$(5)$ & - & - & - & - & 1 & - & - & - & - & - & - \\
$(6)$ & 2 & - & 4 & 5 & 6 & 3 & 4 & 5 & - & - & - \\
$(7)$ & - & - & 2 & 3 & 4 & 2 & 1 & 3 & - & - & - \\
$(8)$ & - & - & 1 & 2 & 3 & 1 & 2 & 1 & - & - & - \\
$(9)$ & - & - & - & - & - & - & - & - & 1 & - & - \\
$(10)$ & 4 & 3 & 6 & 7 & 8 & 6 & 6 & 7 & 3 & 2 & 3 \\
$(11)$ & - & 2 & - & - & - & - & - & - & - & - & 1 \\
\hline
\end{tabular}

Finally, we summarize the frequencies of six efficient units compared with eleven units and Table 5 demonstrates the results of our survey.

Table 5

The frequency of ranks in different cities

\begin{tabular}{lccccccccccc}
\hline Unit & 1 & 2 & 3 & 4 & 5 & 6 & 7 & 8 & 9 & 10 & 11 \\
\hline Azad Shahr & 1 & 0 & 2 & 3 & 1 & 0 & 0 & 0 & 0 & 0 & 0 \\
Bandar Gaz & 2 & 2 & 0 & 0 & 1 & 0 & 3 & 2 & 1 & 0 & 0 \\
Semnan & 1 & 2 & 0 & 0 & 0 & 0 & 0 & 0 & 0 & 0 & 0 \\
Shahrood & 1 & 0 & 0 & 0 & 0 & 0 & 0 & 0 & 0 & 0 & 0 \\
Mehdi Shahr & 1 & 0 & 0 & 0 & 0 & 0 & 0 & 0 & 0 & 0 & 0 \\
Minodasht & 1 & 1 & 0 & 0 & 0 & 0 & 0 & 0 & 0 & 0 & 0 \\
\hline
\end{tabular}

Now we can use Cook and Kress (1990) technique to find the relative ranking and Table 6 summarizes the results of our survey. 
Table 6

The results of the BCC and Cook \& Kross techniques and final ranking

\begin{tabular}{lccccc}
\hline \multirow{2}{*}{ Unit } & \multicolumn{2}{c}{ BCC } & \multicolumn{2}{c}{ Cook and Kress } \\
\cline { 2 - 6 } & Efficiency & Rank & Efficiency & Rank & Final rank \\
\hline Azad shahr (1) & 1 & 1 & 1 & 1 & 1 \\
Bandar Gaz (2) & 1 & 1 & 1 & 1 & 1 \\
Damghan (3) & 0.68 & 9 & - & - & 9 \\
Semnan (4) & 1 & 1 & 0.7491 & 3 & 3 \\
Shahrood (5) & 1 & 1 & 0.4987 & 5 & 5 \\
Aliabad (6) & 0.68 & 9 & - & - & 9 \\
Gorgan (7) & 0.9 & 7 & - & - & 7 \\
Garmsar (8) & 0.83 & 8 & - & - & 8 \\
Mahdishahr (9) & 1 & 1 & 0.4987 & 5 & 5 \\
Gonbad Kaboos (10) & 0.5 & 11 & - & - & 11 \\
Minoodasht(11) & 1 & 1 & 0.4994 & 4 & 4 \\
\hline
\end{tabular}

As we can observe from the results of Table 6, two cities, Azad shahr and Bandar Gaz, are the best candidate for investment followed by Semnan, Minoodasht, Mahdishahr.

\section{Conclusion}

In this paper, we have presented an empirical investigation to measure the relative efficiency of 11 private universities located in region ten of Islamic Azad university. The proposed study of this paper assigned some points for human resources including university professor and regular employees and considered it along with assets as inputs of DEA model. We have also considered the number of graduated students and operating profit as output of our proposed DEA model. The implementation of standard BCC method yielded 6 efficient units and to have better results we have used another DEA technique. The results of this study presented some investment opportunities for management of this private university.

\section{Acknowledgment}

The authors would like to thank the officials of Islamic Azad university for providing necessary information and supporting this project.

\section{References}

Avkiran, N. K. (2010). Association of DEA super-efficiency estimates with financial ratios: Investingating the case for Chinese banks. Omega, 39(3), 323-334.

Anderson, P., \& Peterson, N. C. (1993). A procedure for ranking efficient units in data envelopment analysis. Management Science, 39(10), 1261-1264.

Cook, W. D., \& Kress, M. (1990). A data envelopment model for aggregating preference rankings. Management Science, 36, 1302-1310.

Charnes A, Cooper, W. W., Rhodes, E. (1978). Measuring the efficiency of decision making units. European Journal of the Operational Research, 2, 429-44.

Charnes A, Cooper W. W., Lewin, A., Seiford, L. M. (1994). Data envelopment analysis: theory, methodology and applications. Massachusetts: Kluwer Academic Publishers.

Chen, S. J., \& Hwang, C. L. (1992). Fuzzy multiple attribute decision making: Methods and applications. Berlin: Springer-Verlag.

Fallah, M., Aryanezhadb, M.B., Najafi, S.E., \& Shahsavaripour, N. (2011). An empirical study on measuring the relative efficiency using DEA method: A case study of bank industry. Management Science Letters, 1(1), 49-56. 
Lin, T. T., Lee, Ch-Ch., \& Chiu, T-F. (2009). Application of DEA in analyzing a bank's operating performance. Expert Systems with Applications, 36(5), 8883-8891.

Saaty, T. L. (1992). How to make a decision: the analytic hierarchy process. European Journal of Operational Research, 48, 9-26.

Staub, R. B., Da Silva e Souza, G. \& Tabak, B. M. (2010). Evolution of bank efficiency in Brazil: A DEA approach. European Journal of Operational Research, 202(1), 204-213.

Yang, J.B., Wong, B.Y.H., Xu, D.L., Liu, X.B. \& Steuer, R.E. (2010). Integrated bank performance assessment and management planning using hybrid minimax reference point - DEA approach. European Journal of Operational Research, 207(3), 1506-1518.

Zaheri, F., Farughi, H., Soltanpanah, H., Alaniazar, S., \& Naseri, F. (2012). Using multiple criteria decision making models for ranking customers of bank network based on loyalty properties in weighted RFM model. Management Science Letters, 2(1), 697-704. 